\title{
The Effectiveness of River Bank Normalization on Flood Risk Reduction
}

\author{
I Gede Tunas ${ }^{1, *}$, and Rudi Herman ${ }^{1}$ \\ ${ }^{1}$ Department of Civil Engineering, Universitas Tadulako, Palu, 94117, Indonesia
}

\begin{abstract}
One popular technique used to reduce flood risk associated with a flood mitigation scheme, is normalization of a river bank. This method can be effected done by adjusting the width of the river on the left and right banks, in order to increase channel capacity. The biggest obstacle most often encountered in adjusting the river banks is insufficient land area, both on the left and right sides. The capacity of the river channel can therefore not be optimised, due to this limitation. This study intends to evaluate the effectiveness of river bank normalization to reduce flood risk in the Puna River, Central Sulawesi Province of Indonesia. The capacity evaluation was conducted under two conditions i.e. before and after normalization of the river bank, using HEC-RAS Hydrodynamic Program, integrated with GIS. The level of effectiveness is measured by a comparison between the capacity of the river channel after bank normalization with the required channel capacity on 100 years return period of discharge for important and high-risk river categories. Simulation results in both conditions show that the normalization of river banks can increase channel capacity from $270 \mathrm{~m}^{3} / \mathrm{s}$ to $470.2 \mathrm{~m}^{3} / \mathrm{s}$, where the required channel capacity is $590.71 \mathrm{~m}^{3} / \mathrm{s}$. The effectiveness of the bank normalization is $100 \%$, included in the category of very effective
\end{abstract}

\section{Introduction}

Flooding is one of the disasters that threaten people in various regions of the world, including in Indonesia [1-2]. Floods can occur at any time and have a very significant impact on various aspects, including physical and non-physical [3-5]. Therefore, efforts are needed to reduce the risk of disasters, both structural and non-structural protection in the river and watershed systems [6-7]. Structural protection can be done in various ways such as levees, retention ponds or flood storage, short-cut channels, bank normalization and others, where the emphasis is on increasing the channel capacity and reducing inflow. Structural protection should also be accompanied by non-structural efforts such as controlling the utilization of natural resources in watersheds, structuring the use of river banks, and preventing waste disposal in the river [8-9].

Protection from flood hazard is implemented based on the level of importance of protected areas or facilities. The higher the importance of the level of protection, the greater the standard of design used [10]. Important areas such as densely populated settlements,

*Corresponding author: tunasw@yahoo.com 
public infrastructures such as highways, railroads, airports, and other important facilities require high levels of security protection against flood hazards. This is intended to minimise and reduce damage when flood protection and flood prevention efforts fail [1112].

Generally, flood prevention effort should be evaluated after operating within a certain period. It is intended to identify the level of effectiveness of the efforts due to various characteristic changes, both in the upper watershed and in the river channel [13]. Erosion on the upper watershed and sedimentation in the river channel may result in reduced river flow capacity, therefore evaluation of the cross-sectional capacity should always be undertaken.

\section{Material and Method}

\subsection{Materials}

The case study was conducted in the Puna River, the second largest river in Poso Regency, Central Sulawesi, Indonesia. As shown in Fig. 1, the basin of Puna is an area of roughly $772.2 \mathrm{~km}^{2}$. It covers tropical rain forest in the upper and middle zones, agricultural land, and a settlement area in the lower zone, with many public facilities, such as transportation infrastructure, electrical transmission and distribution networks, clean water and sanitation facilities, airport area, and many other supporting facilities. This area is a buffer zone of Poso city, which is located approximately $3.7 \mathrm{~km}$ to the east. Geographically, the basin is situated between longitude $120^{\circ} 24^{\prime} 13.19^{\prime \prime} \mathrm{E}$ and $120^{\circ} 40^{\prime} 26.45^{\prime \prime} \mathrm{E}$ and latitude $1^{\circ} 22^{\prime} 29.17^{\prime \prime} \mathrm{S}$ and $1^{\circ} 50^{\prime} 31.34^{\prime \prime S}$. Two thirds of the basin is comprised of a forest area with hilly and mountainous topography, and the remaining area is flat and has been developed for supporting community life.

As a buffer zone of Poso City, Puna River and the surrounding area play an important role in the provision of urban support facilities, in this case, Kasiguncu Airport and main access connecting Poso City. The airport is situated on the right side of the floodplain of Puna River, and covers an area of approximately 105 ha (Fig.2). It is also supported by agricultural land and fisheries on the left side of the Puna River.

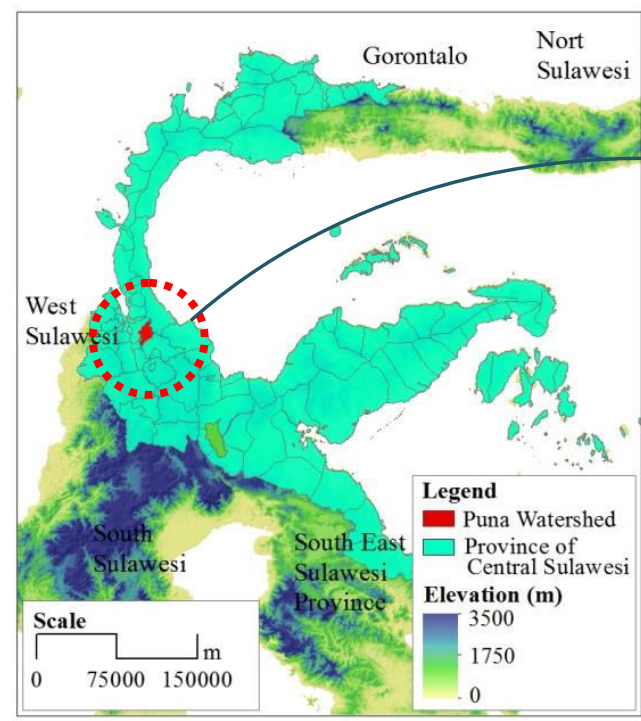

Province of Central Sulawesi

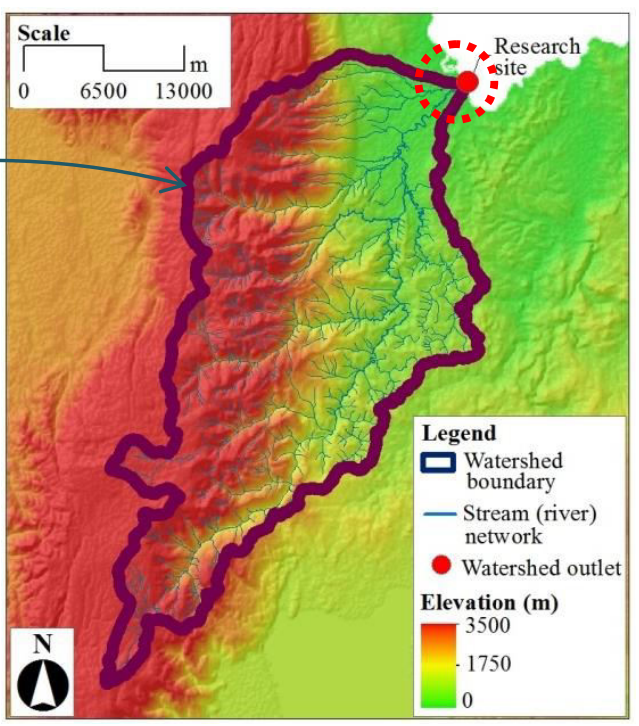

Watershed of Puna

Fig. 1. Study area 


\subsection{Data Collection}

The data that would be used in this research is mainly derived from the downstream reach configuration of the Puna River, approximately $3.7 \mathrm{~km}$ from the estuary, as shown in Fig. 2. The configuration covers more detailed situations and sections both pre and post normalization. The average depth and width of the existing geometry is $1.5 \mathrm{~m}$ and $45 \mathrm{~m}$ respectively. The normalized geometry is increasing the cross-sectional dimension to be 2.5 $\mathrm{m}$ deep and $80 \mathrm{~m}$ wide (Fig. 3).

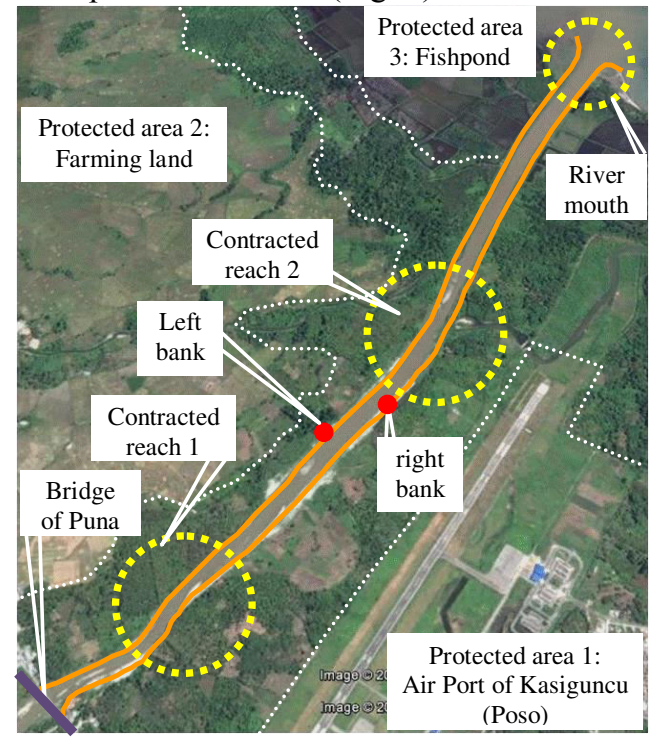

a) exisiting outside bank lines

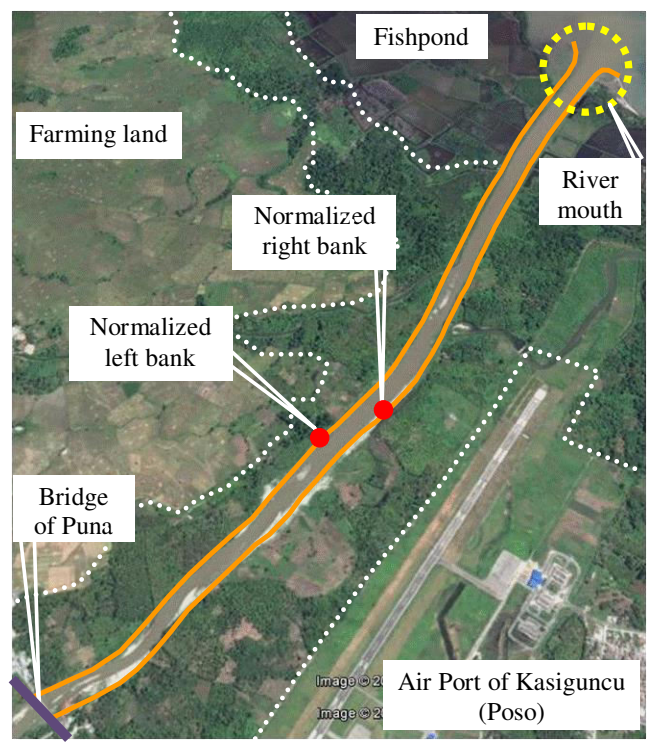

b) normalized outside bank lines

Fig. 2. Description area of normalized Puna River banks

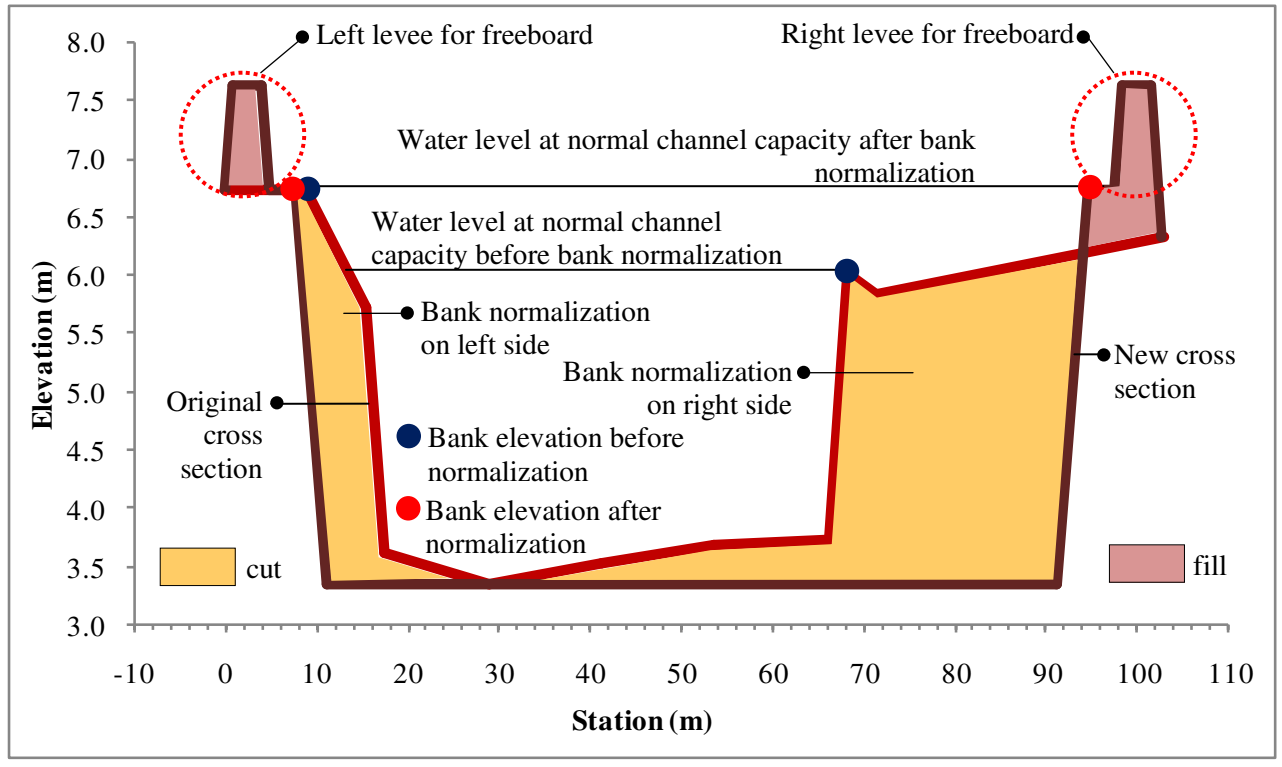

Fig. 3. Typical bank normalization of Puna River (CS.34) 
Further data for supporting the analysis are the design flood and tide of the Puna River. Design flood is obtained by frequency analysis, based on maximum rainfall recorded at the hydrology station in the watershed area for a period of more than 10 years. The design flood for a certain return period, derived from analysis using a series of statistical distribution tests, can be seen in Fig. 4. The tidal data is obtained by direct measurements in the Puna River mouth and would be used to determine the highest water level in the river outlet, by using harmonic analysis. The measurement is carried out using the automatic water level recorder for 15 days in January 2018. The data result from the investigation is in the form of hourly water level as shown in Fig. 5. Based on the tidal curve, it can be inferred that it is of mixed semidiurnal type.

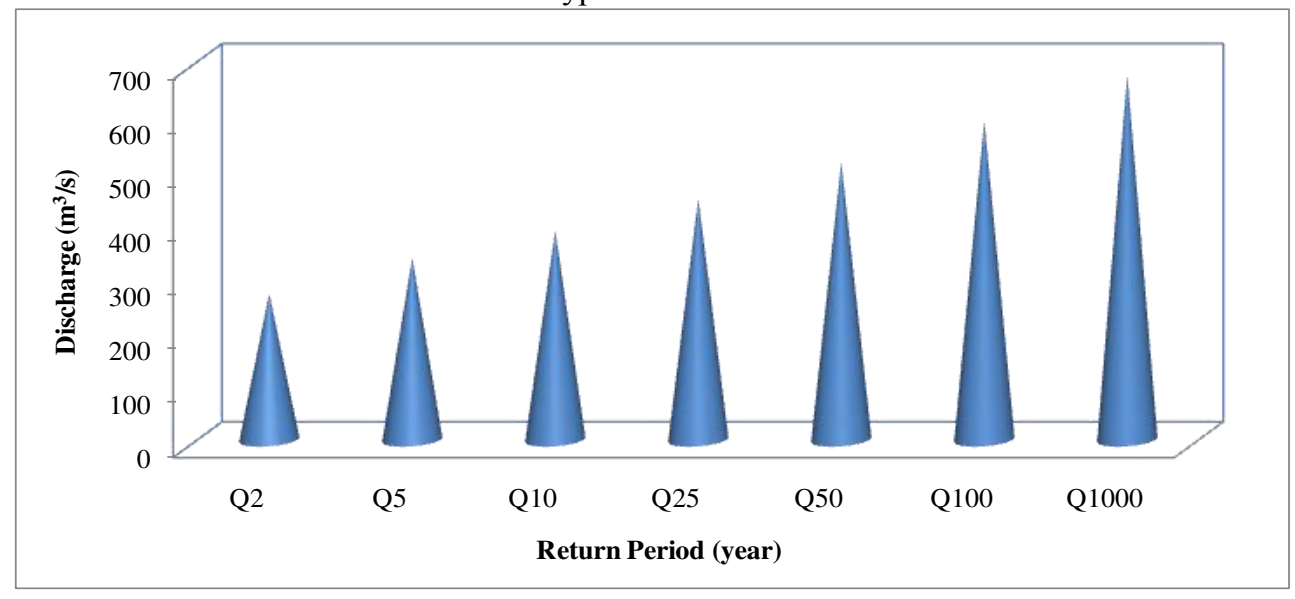

Fig. 4. Design flood of Puna River

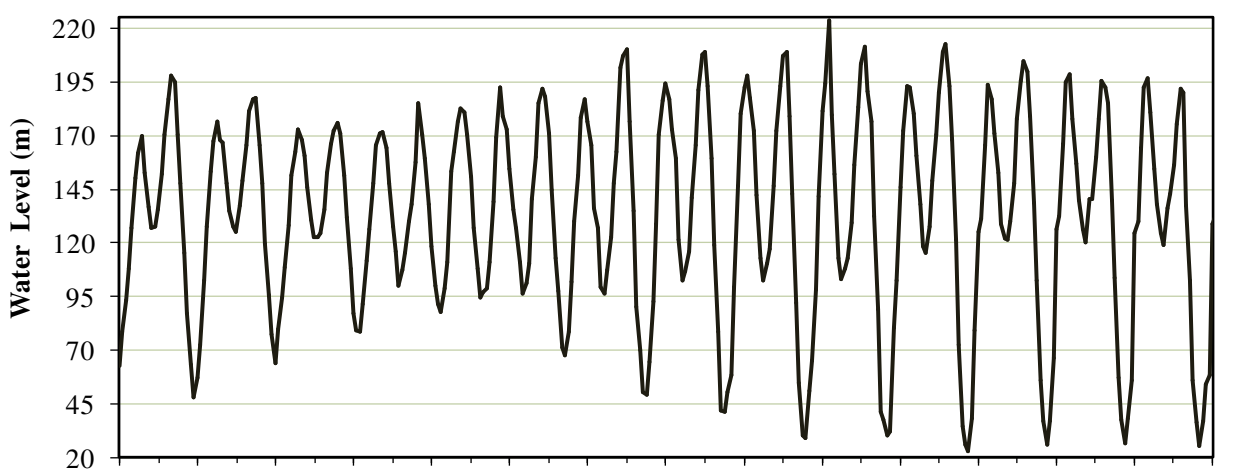

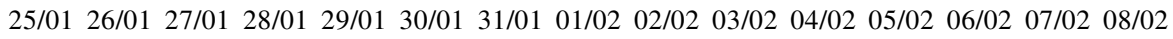

Time (hour)

Fig. 5. Tidal data near the estuary of Puna River for 15 days from January 25, 2018 to February 8 , 2018

\subsection{Methods}

The present study is intended to evaluate the effectiveness of river bank normalization on flood risk reduction, especially in the downstream reach of the Puna River. The crosssection capacity before and after bank normalization is assessed using HEC-RAS hydrodynamic Model [14]. Model calibration is done by first adjusting the roughness coefficient of cross-sectional material to obtain a good model performance. Data, input as upstream boundary condition is the design hydrograph of 100 years return period. The 
choice of return period depends on various factors, including the importance of the protected area and the structure and risk of levee failure [10]. The most important potential failure threatening levee or embankment include: flooding from high precipitation, flooding from levee failure, earthquakes, and landslides.

The downstream boundary condition is the water level in the form of design tidal curve. Tidal constants, derived using harmonic analysis, are used to generate design tidal curve. Furthermore, based on these two boundary conditions, hydraulic simulation can be performed in the type of unsteady analysis. The simulation is also conducted in two terms that are both before and after normalization.

The performance of bank normalization is evaluated using an effectiveness approach. Effectiveness is a measure of successful achievement that has been previously set. In this case, the effectiveness would be measured by the ability of the bank normalization to pass the flood of 100 years return period [14-15]. The effectiveness of bank normalization can be measured using a ratio of effectiveness, as referred to in Table 1.

Table 1. Reference standards of effectiveness [15]

\begin{tabular}{|c|c|}
\hline The ratio of effectiveness (\%) & Level of performance \\
\hline Below 40 & Not very effective \\
\hline $40-59.99$ & Not effective \\
\hline $60-79.99$ & Fair/moderate \\
\hline 80 and above & Very effective \\
\hline
\end{tabular}

\section{Results and Discussion}

\subsection{Channel Capacity}

The channel capacity can be known by simulating the flow with a 100 year return period. Based on Fig. 6, it is seen that the elevation of the river bank is exceeded in CS.34 to CS.72 along $2067.05 \mathrm{~m}$. This indicates that the cross-sectional capacity of the Puna River is under a 100 year return period of flow. The 100 year return period of flow is $590.71 \mathrm{~m}^{3} / \mathrm{s}$. A series of trial simulations were also performed to determine the channel capacity. By inputting some discharges under the 100 year return period, it can be seen that the channel capacity of the Puna River is $470.2 \mathrm{~m}^{3} / \mathrm{s}$.

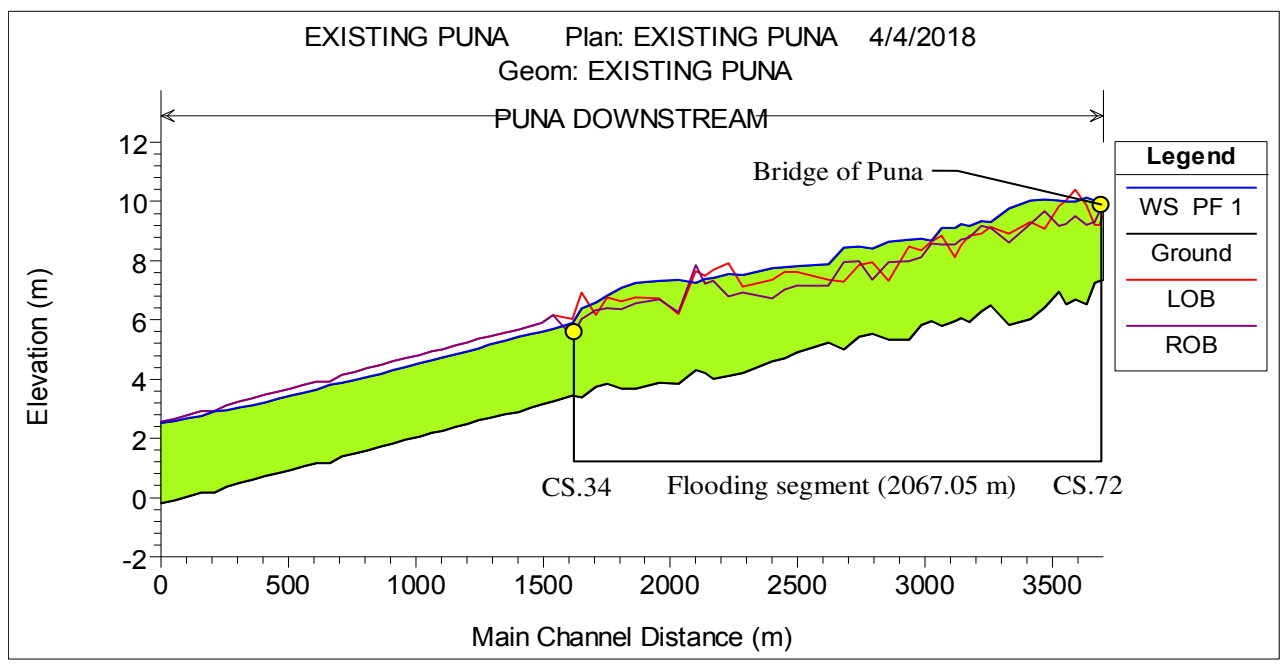

Fig. 6. Water surface profile before bank normalization with 100 year design flood 
The limitation of bank capacity in this section is caused by channel contractions and bed aggradations due to continuous sedimentation over a long time. Sediment deposition generally occurs on the left and right sides of the channel, especially on the inner side of the river bend. The river bottom slope contributes greatly to the sediment deposition process. The downstream river segment generally has a lower bed slope than the middle and the upstream sections. Hydraulically, when the bed slope of the river is low then the flow velocity is also low [16]. Low velocities of flow potentially lead to higher intensity of sediment grain deposition and followed by a change in cross-sectional configuration, cause a reduction channel capacity of the river.

Sediment transport in the Puna River is relatively very high, especially in the rainy seasons. The Puna River has many tributaries that contribute to sediment deposition in the downstream segment. Most sediment deposition stems from surface erosion in the upstream basin, due to intensive land conversion for agricultural land and plantation areas. The government, through the Forestry Agency of Central Sulawesi Province, has made attempts to reduce the rate of land use conversion by means of various programs, one of them is land conservation in the forest area. However, conservation programs require a very long recovery time, so the impact on reducing erosion has not yet shown significant results.

In addition, sand mining for building materials in the middle and upstream segments also contributes to sediment deposition in the downstream reach. Sand removal at the bottom of the river can lead to a decrease in the stability of the river banks. Flow fluctuations over a period of time will cause erosion on unstable banks. The result of this erosion will be carried by the stream to the downstream and deposited, before arriving at the estuary. In the long term, this erosion and sedimentation process not only leads to reduced cross-sectional capacity but also causes configuration change of the river channel over time. Therefore, sand mining activities in this area must be ceased immediately.

\subsection{Effectiveness of Bank Normalization}

The bank normalization is done along 2,067.05 m, from CS.34 to CS.72. As explained earlier, the width of the river bed is increased from $60 \mathrm{~m}$ to $80 \mathrm{~m}$. The elevation of river banks on the left and right channels are also raised. The simulation of discharge at a 100 year return period shows that the capacity of the river channel has been reached. The water level elevation on all river stations along $3.7 \mathrm{~km}$ is below the river bank elevation (Fig. 7).

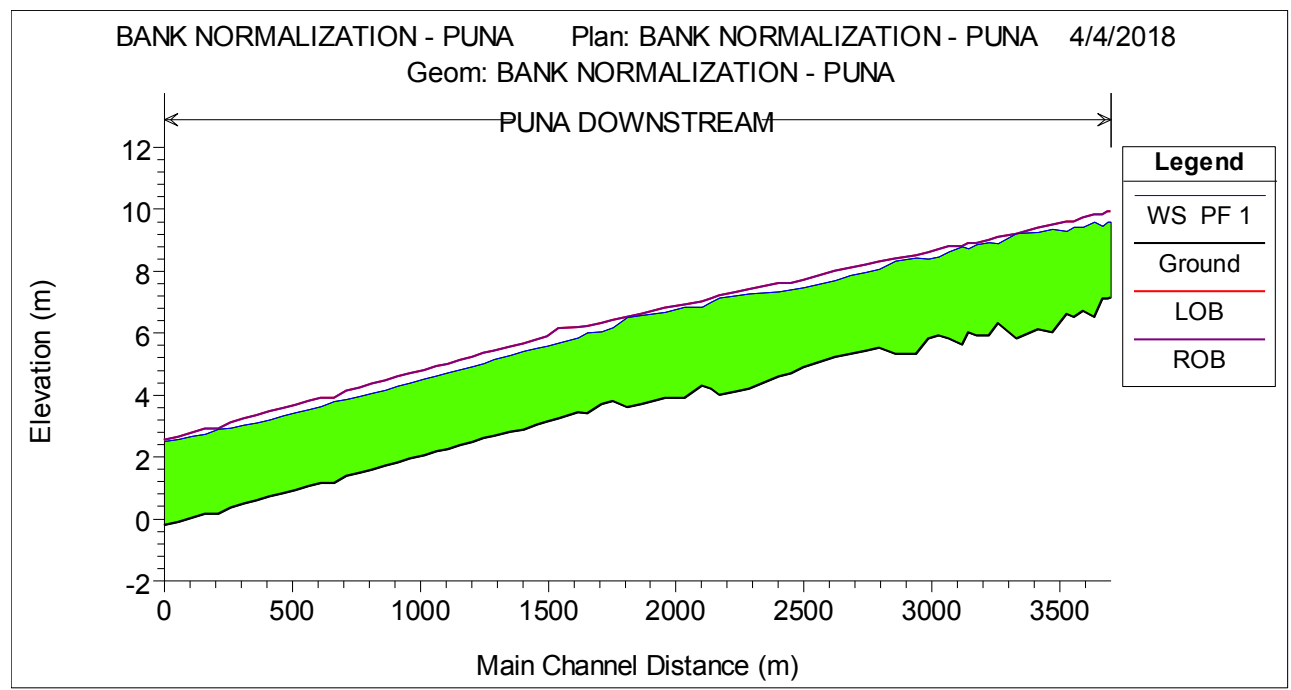

Fig. 7. Water surface profile after bank normalization with 100-year design flood 
The increase of channel capacity shows that the design capacity of the Puna River for the protection of important areas and facilities, especially Kasiguncu Airport has been met. The effectiveness of the bank normalization, which defined as the ratio of realisation of bank normalization capacity to channel capacity required, is $100 \%$, included in the very effective. Furthermore, the effectiveness of this cross-sectional capacity needs to be followed by the stability of the bank along the normalized segment. This is done to prevent local scouring, especially in the outer side of the river bends due to increased flow velocity. The high flow velocity on the outer side of the bend has the potential to erode the river bank due to the absence of bank protection. For that reason, bank protection methods such as flow diversion structure, revetments and the others, can be applied [17-18].

Basically, an increase in cross-sectional capacity can also be done by adjusting the slope of the river bed. The slope of the river bed is modified to increase flow velocity. Hydraulically, the bad slope positively correlated with flow velocity. In the velocity equation, the larger the slope of the river bed, the higher the flow velocity, and the greater the flow that can be passed. However, the bed slope arrangement should also be based on the characteristics of sediment transport in the river, to maintain the balance of incoming sediment transport and sediment transport out [19-20].

\section{Conclusion}

The finding of this research proves that bank normalization of the Puna River, especially in the downstream reach is very effective to pass the flood of a 100 year return period. Simulation results in both conditions show that the normalization of river banks can increase channel capacity from $470.2 \mathrm{~m}^{3} / \mathrm{s}$ to $590.71 \mathrm{~m}^{3} / \mathrm{s}$, where the required channel capacity is $590.71 \mathrm{~m}^{3} / \mathrm{s}$. The effectiveness of the bank normalization, which defined as the ratio of realisation of bank normalization capacity to channel capacity required, is $100 \%$, included in the category of very effective.

Authors thank the River Basin Bureau of Sulawesi III-Ministry of Public Work and Housing Republic of Indonesia and Water Resources Board of Central Sulawesi Province for providing the rainfall and discharge data at the study area.

\section{References}

1. K.T. Lendering, S.N. Jonkman, M. Kok, J. Flood Risk Manage., 9(4), 320-334, (2016)

2. M. Aslam, Mehran Univ. Res. J. Eng. Technol., 37(2), 297-314, (2018)

3. I.G. Tunas, R. Maadji, Int. J. Adv. Sci. Eng. Inform. Technol. (IJASEIT), 8(6), 24132420, (2018)

4. J.K. Poussin, W.J.W. Botzen, J.C.J.H. Aerts, Global Environ. Change, 31, 74-84, (2014)

5. P.J.A. Baan, F. Klijn, Int. J. River Basin Manage., 2(2), 113-122, (2004)

6. A. Domeneghetti, S. Gandolfi, A. Castellarin, L. Brandimarte, G.D. Baldassarre, M. Barbarella, A. Brath, J. Flood Risk Manage., 8(4), 301-314, (2015)

7. M. Farid, H.H. Pusparani, M.S.B. Kusuma, S. Nastasaputra, MATEC Web of Conferences, 05003, (2017)

8. N. Sukegawa, Int. J. Water Resour. Dev., 4 (1), 8-17, (1988)

9. K. Sung, H. Jeong, N. Sangwan, D.J. Yu, Water Resour. Res., 54(4), 2661-2680, (2018) 
10. V.M. Ponce, Engineering hydrology: principles and practices, 1st ed., Prentice Hall, New Jersey, (1994)

11. P. Hudson, W.J.W. Botzen, H. Kreibich, P. Bubeck, J.C.J.H. Aerts, Nat. Hazards Earth Syst. Sci., 14, 1731-1747, (2014)

12. S.A. Choi, C.S. Yi, M.P. Shim, H.S. Kim, J. Korea Water Resour. Assoc. 40(5), 383396, (2007)

13. S. Harto, Hydrology: teory, problem and solving, 1st ed., Nafiri Offset, Yogyakarta, (2000) [in Indonesian]

14. I.G. Tunas, Simulation model of flood control system using HEC-RAS and GIS, M. Eng. Thesis, UGM, (2004) [in Indonesian]

15. V.B. Kondalkar, Organization effectiveness and change management, PHI Learning, New Delhi, (2013)

16. I.G. Tunas, R. Maadji, A. Rusdin, Proceeding of International Conference on Infrastructure Development, 158-166, (2013)

17. H. Nakagawa, H. Zhang, Y. Baba, K. Kawaike, H. Teraguchi, J. Flood Risk Manage., 6(4), 345-359, (2013)

18. F. Klijn, M.V. Buuren, S.A.M. Rooij, J. Human Enviro., 33(3),141-147, (2004)

19. S.L. Yang, J. Zhang, S.B. Dai, M. Li, X.J. Xu, J. Geophys. Res. 112, 1-13 (2007)

20. C. Miao, D. Kong, J. Wu, Q, Duan, Sci.Total Environ., 551-552, 16-22, (2016) 